\title{
GHANGES IN THE FEMORAL NECK IN CONTACT WITH AN ACRYLIC PROSTHESIS
}

\section{Examination of a Necropsy Specimen}

\author{
P. Gowans Laing, Pfabery, and H. Docglas Ross, London, England
}

The evolution of a new technique of arthroplasty of the hip joint has been described by the Judet brothers $(1949,1950)$. This operation involves the resection of the femoral head and the insertion of an acrylic prosthesis in substitution. Although many workers have

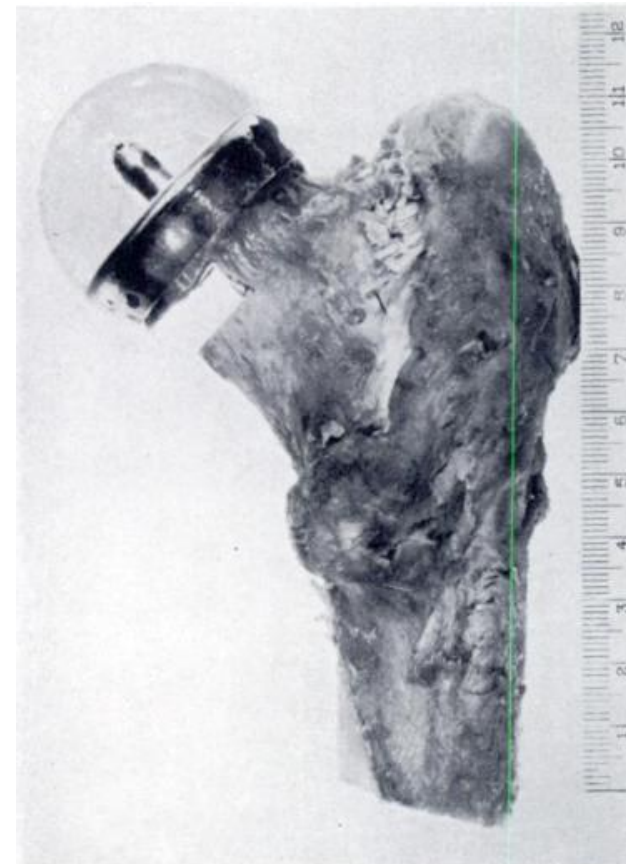

FIG. 1

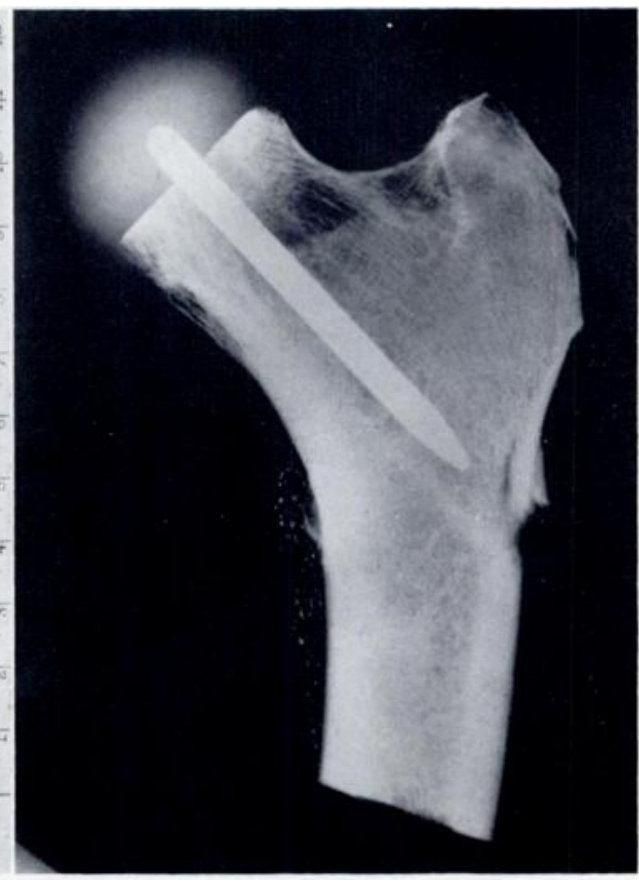

Fig. 2

Cpper end of femur with prosthesis in situ. The area from which tissue was removed for histological examination can be seen. Figure 2-Radiograph of the specimen.

reported cases treated in this way, we have been unable to find any account of the subsequent pathological changes in the bone of the femoral neck. We are, therefore, reporting our findings in the femoral neck from a patient who died two weeks after the performance of an operation of this type.

\section{CASE REPORT}

A woman aged seventy years, suffering from crippling osteoarthritis of the right hip joint, was treated by a Judet-type arthroplasty. The technique of the operation was similar to that of the Judet brothers, and only a few points need be mentioned. The joint capsule was excised as completely as possible. The canal in the femoral neck, into which the stem of the prosthesis was to be inserted, was started with a hand drill and finally enlarged with the special Judet instrument; at no time was any high-speed drilling done, and no burning of tissues could have occurred. The prosthesis was inserted with minimal force. 


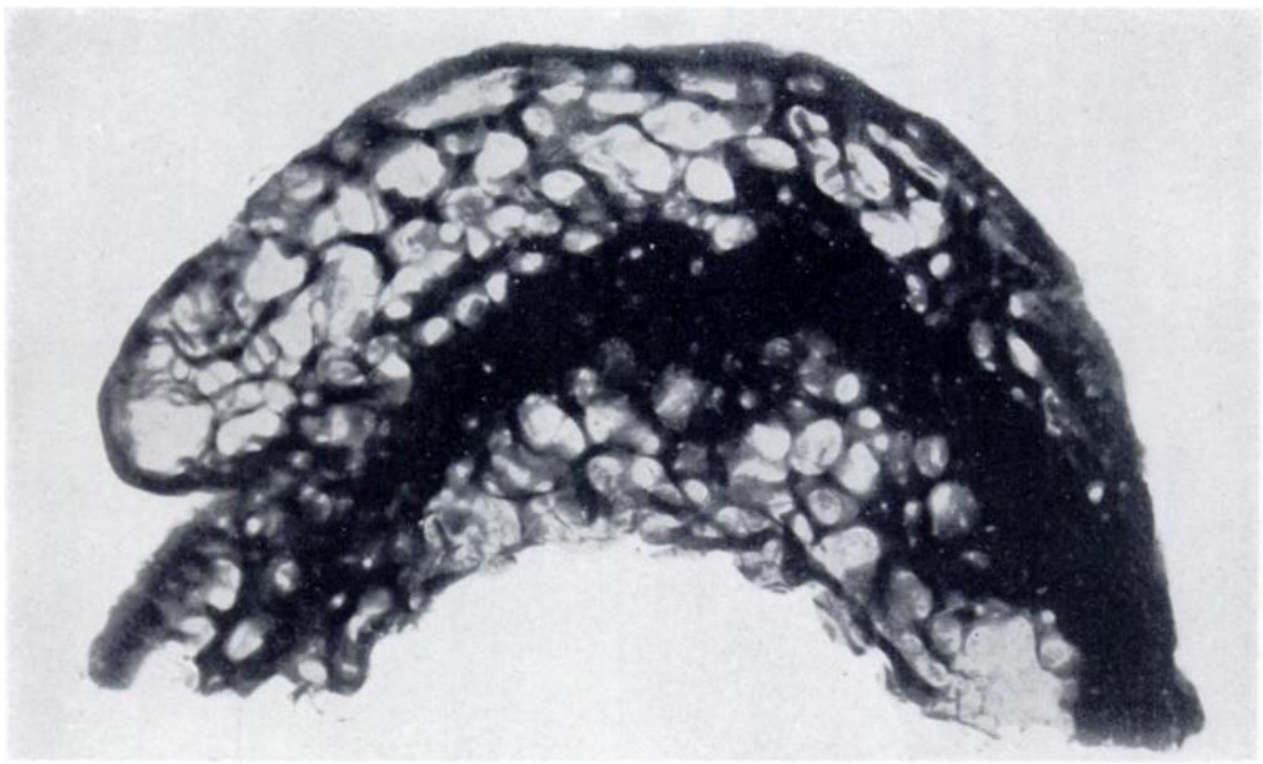

FIti. 3

Cristallography-tube radiograph of part of bone selected for study. Note the corrugations on its concave margin corresponding with those of the stem of the prosthesis $(.6)$.

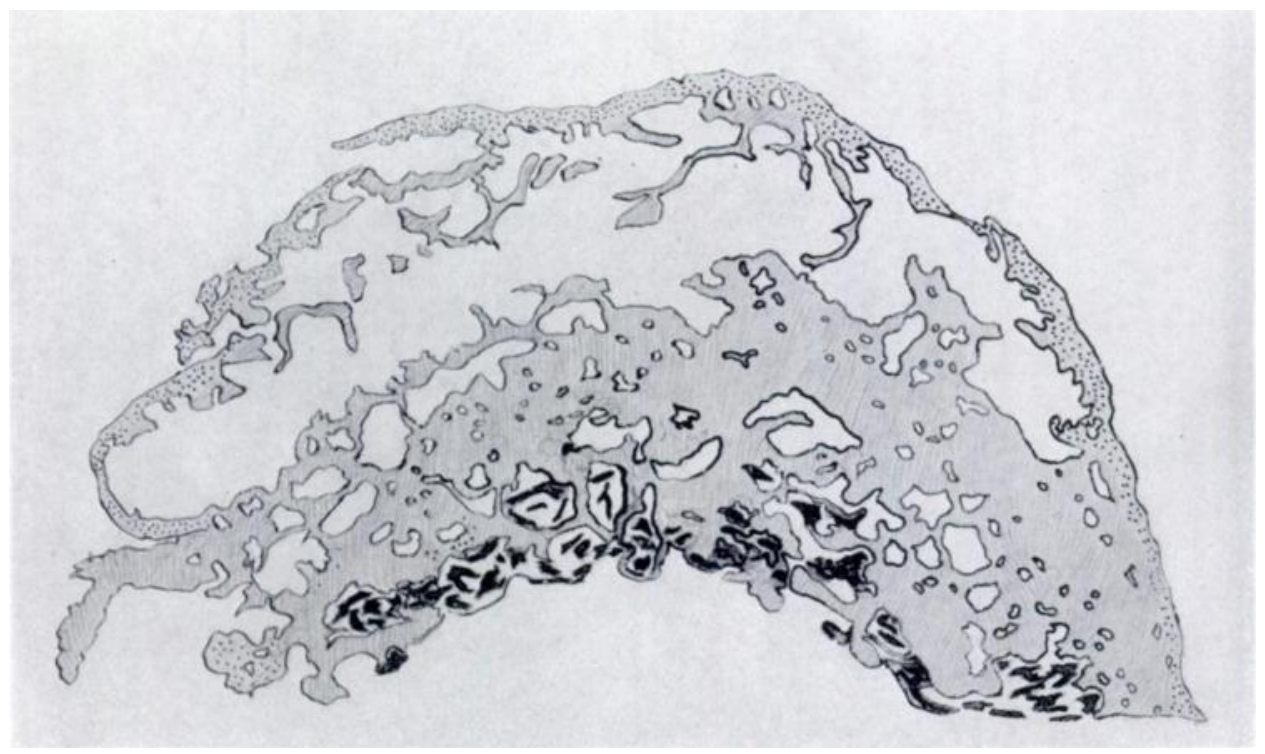

FIG. 4

Photodrawing of low power photomicrograph of section showing areas corresponding to shadows in Figure 3. Black shading - comminuted trabeculae and necrotic myeloid debris. I.ight shading dead bone. Stippling-nucleated bone $(\cdot 6)$. 
Death from pulmonary embolism occurred two weels after the operation. At the post-mortem examination the upper quarter of the femur was removed for investigation (IFig. I). Pathological examination-The prosthesis was found to be firmly fixed in the femoral neck and a radiograph of the specimen ( $\mathrm{Fig} .2$ ) showed no rarefaction of the bone around its stem. A block of bone from the postero-medial aspect of the femoral neck (Fig. I) was removed close to the overlap of the prosthesis. The internal margin of this block comprised the bone in intimate relationship to the stem of the prosthesis. Radiography of this block by crystallography tube (Fig. 3) revealed three main zones, consisting of outer and inner trabeculated areas with dense shadow intervening.

Zone 1---Inner zone of cancellous bone, having a corrugated surface where it was in contact with the stem of the prosthesis and merging with

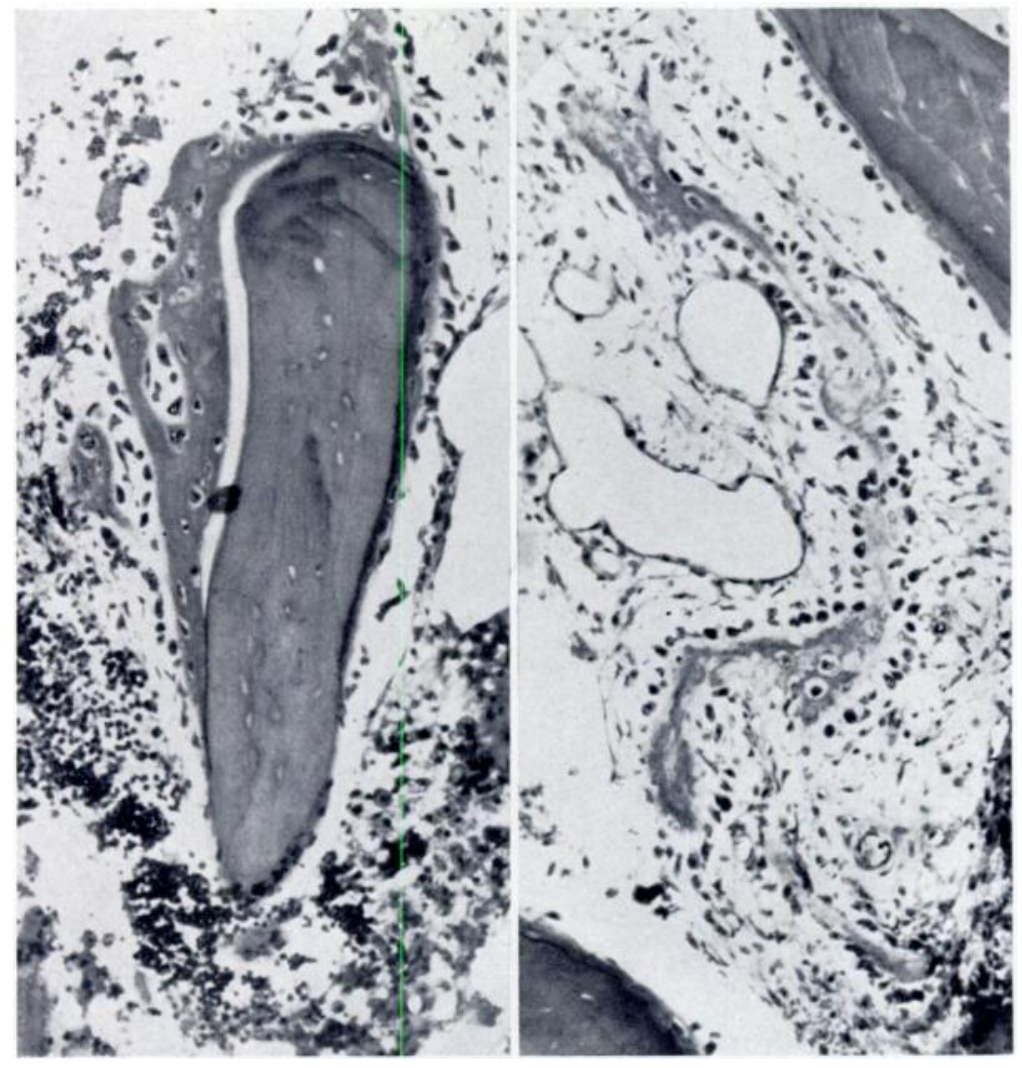

FIG, 5

Fic. 6

Photomicrographs from Zone 1 -In Figure 5 there is a small sheath of new bone formation on one side of a fragment of dead bone. A focus of new bone formation is seen in Figure $6(\times 160)$.

Zone 2-consisting of dense compact bone of the calcar femorale which in turn gives place to Zone 3-external trabeculated bone.

The histological changes encountered may be conveniently grouped in correlation with these zones (Fig. 4). In Zone 1 the trabeculated bone was necrotic and the medullary spaces were filled with comminuted fragments of bone and necrotic myeloid debris. There were occasional foci of vascular mesenchymal proliferation, and osteoblastic activity was clothing some of the necrotic trabeculae with new bone (Fig. 5). Where Zone 1 merged with Zone 2 the medullary spaces contained less debris but were filled with lipoid phagocytes. Zone 2 , comprising the calcar femorale, was the site of almost universal necrosis, as evidenced by the empty lacunae 
and disappearance for the most part of the endosteal tissues and contents of the Haversian canals, some of these showing thrombosis of their vessels (Fig. 5). Some of the larger medullary spaces contained normal myeloid tissue and in these instances occasional osteocytes were present in lacunae of the adjacent bone. In Zone 3 the most superficial of the peripheral external bone was nucleated but all the remainder of the trabeculae consisted of necrotic bone. The intertrabecular spaces were occupied by normal vascular mesenchyme with slight infiltration of lipoid phagocytes. No reactive proliferation was seen.

Thus the appearances were those of extensive bone necrosis involving an important weight-bearing area of the femoral neck-namely, the calcar femorale. This necrosis was not of block infarct type, for it was more irregular in its occurrence and had not elicited a marked inflammatory reaction.

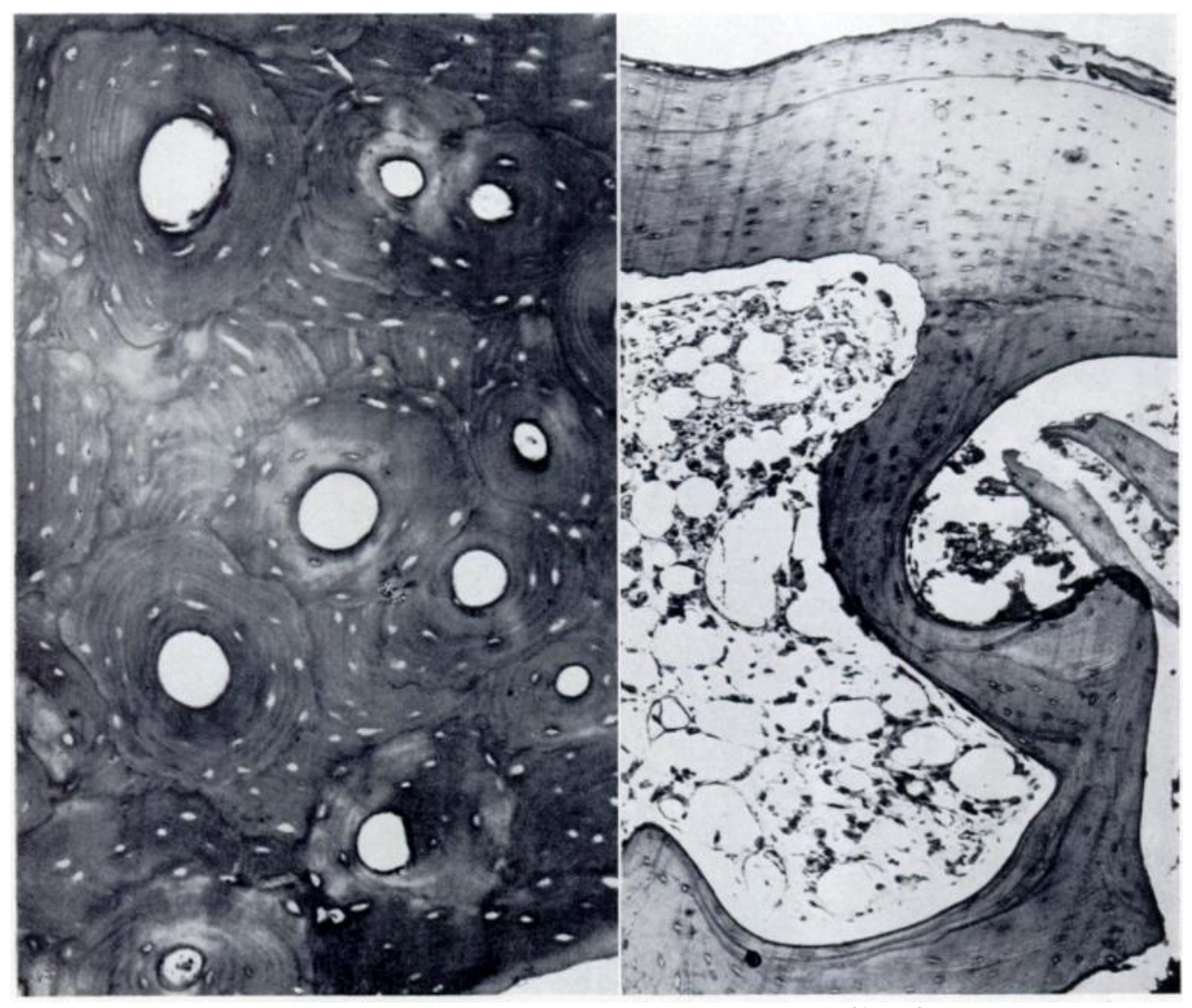

FIG. 7

FIG. 8

Figure 7-Photomicrograph from Zone 2. Note the almost universal absence of osteocytes from lacunae and the empty Haversian canals $(<160)$. Figure 8-Photomicrograph from Zone 3. The most superficial bone is seen to be nucleated. Lipoid phagocytes are seen among the tissues of the intertrabecular spaces $(\times 80)$.

\section{SUMMARY}

A Judet-type arthroplasty of the hip was performed. The patient died fourteen days after the operation. The upper end of the femur was examined and showed extensive necrosis surrounding the stem of the prosthesis.

\section{REFERENCES}

JUDET, R., and JUnET, J. (1949): Essais de reconstruction prothétique de la hanche après résection de la tète fémorale. Journal de Chirurgie, 65, 17.

Jedet, J., and Junet, R. (1950): The Use of an Artificial Femoral Head for Arthroplasty of the Hip Joint. Journal of Bone and Joint Surgery, 32-B, 166. 